\title{
Fee collection in community based corrections
}

\begin{abstract}
Offenders sentenced to serve community-based sentences are usually required to pay fees to cover expenses associated with programs and services they receive.Fees are imposed because community corrections agencies do not have sufficient resources to meet the needs of offenders, especially a growing number of high risk offenders who are suffering from serious mental health and addiction symptoms.Collecting fees from these offenders is a necessity, but it poses unique challenges. This case study examines the pressing need to collect fees from those serving community-based sentences.
\end{abstract}

Keywords: fees, fee collection, community-based corrections, community based sentences, correctional philosophy, mass incarceration, selective incarceration, probation, parole

\author{
Volume 5 Issue 2 - 2017
}

\author{
Michael P Brown, Taylor Day, Melinda Jones, \\ Lindsey La Fleche \\ Department of Criminal Justice and Criminology, Ball State \\ University, USA
}

\begin{abstract}
Correspondence: Michael P Brown, PhD and Chairperson, Department of Criminal Justice and Criminology, Ball State University, 2000 W. University Avenue, Muncie, Indiana, 47306, USA, Tel 765-285-5979, Fax 765-285-5912,

Emailmbrown@bsu.edu
\end{abstract}

Received: July 20, 2017 | Published: July 27, 2017

\section{Introduction}

Decades of prison and jail crowding in the United States have resulted in a shift in correctional philosophy, from one that supported mass incarceration to one that increasingly places a priority on selective incarceration and the use of community-based sentences. According to the latest census of correctional populations, offenders serving probation and parole sentences are by far the largest offender group, totaling 4,660,300. By comparison, prison and jail inmates numbered 2,255,000. Hence, about 70 percent of all persons under correctional supervision are serving out their sentences in the community. ${ }^{1}$ The pressure to supervise more diverse and higher risk offenders in the community has never been greater than today, and the economic decline that followed from the Great Recession in 2008 has raised complex questions about how to adequately fund the supervision of these offenders in the community. Statutes have existed since the late 1980s that allow criminal courts to impose fees on offenders serving community-based sentences. These fees are intended to recover the costs associated with providing rehabilitation programming, supervision and monitoring services, and probation/ parole officer training. ${ }^{2}$

Opinions vary considerably about the imposition of fees on offenders. While some practitioners and policy analysts are in favor of fee collection, others contend that it is unfair, unreasonable, and unprofessional.Perhaps the most commonly mentioned reason cited by community corrections professionals for being opposed to collecting fees is that it undermines their "helper" role. That is, when the officer or agent spends time with an offender, it is far more important, they contend, to be addressing criminogenic or behavioral concerns than it is to be spending time collecting fees. Moreover, spending time collecting fees may give the impression to an offender that their welfare and rehabilitation are secondary considerations.Proponents, on the other hand, argue that paying fees may have therapeutic effects on offenders. That is, paying fees involves taking responsibility for one's actions; it develops a sense of accomplishment and self-efficacy. This would be especially true for offenders who make considerable sacrifices in order to regularly pay fees. Hence, paying fees may teach offenders that self-sacrifice and perseverance are keys to achieving legitimate life goals. But what do we know about fee collection?Is it therapeutic?Are the fees truly needed by agencies to deliver services that help bring about behavioral change and keep communities safe?If so, what do we know about the best ways to collect fees?

\section{Case presentation}

Is fee collection therapeutic?To date, no causal relationship has been found to show that paying fees is therapeutic for offenders or that it reduces recidivism. There is some evidence, however, that there is a strong association between paying fees and successfully completing a community-based sentence. For instance, one study found that the fee collection rate was about 80 percent among those who successfully completed their probation sentences. On the other hand, the fee collection rate was only 25 percent for those who violated conditions of probation and had their community-based sentence revoked. ${ }^{3}$ While a relationship has not consistently been found between paying fees and rehabilitation, fee collection supports the programs that have been shown to be related to behavioral change and crime reduction.

Are fees needed for agencies to deliver services that help bring about behavioral change and keep communities safe? The change in sentencing philosophies has resulted in reallocating resources that were once used to house prison inmates. Instead, many state departments of correction are now sending more money to the local level to support the supervision and rehabilitation of probationers and parolees.Unfortunately, the redistribution of resources is generally inadequate, resulting in larger caseloads to supervise and inadequate rehabilitation services to meet the diverse and chronic mental health and substance abuse needs found among many of today's probationers and parolees. ${ }^{4}$ Consequently, many jurisdictions look to fee collection as a way to fill the gap between what is allocated from state coffers and what is needed to perform professional, evidence-based community supervision. Therefore, whether one is opposed to fee collection or in support of it, there is no denying that fee collection is a financial necessity in most jurisdictions.Administrators struggle to pay agents 
and support staff commensurate salaries, insurance, and other benefits. They also seek to provide training and resources that are consistent with "best practice" in community-based corrections.

What do we know about the best ways to collect fees? While there is no widely accepted method that is considered "best practice" in collecting fees from those serving sentences in the community, there are five general practices that seem to increase offender compliance with paying fees. First, the collection of fees is largely influenced by agency priorities. If the probation or parole agency places a priority on fee collection, more fees are collected. ${ }^{5}$ Second, setting fees at realistic levels is an important part of effective fee collection. Unrealistically high fees increases noncompliance, which is probably a function of frustration and a sense of hopelessness. Setting fees too low makes efforts to collect fees cost prohibitive. Hence, at the very least, fees should be set at levels that cover correctional expenses plus the cost of collecting fees. Third, a fee collection policy should have clearly written procedures and they should be consistently followed. ${ }^{6}$ Offenders should be given a specific date each month, for instance, when payment is due and how fee collection is enforced when payments are not made. Decision makers should exercise prudence when evaluating ability to pay.

Waiving or suspending fees are appropriate for the indigent and those for which the payment of fees would cause a severe hardship on them and their families. Fourth, fee collection is improved when reminder notices are sent to offenders through the mail and payment is made to someone other than the supervising officer. The supervising officer should be regularly updated on whether the offender is compliant with paying fees. Fifth, when agencies have direct access to at least a portion of the fees collected, then the amount of fees collected increase. Access to revenues from collected fees provides tangible evidence that efforts to collect fees provide support for probation and parole officers and support staff to do their jobs.

\section{Discussion}

The current state of affairs in community-based corrections reflects the convergence of numerous complex phenomena. Decades of mass incarceration have caused prison and jail crowding across the US. Pressures to reform corrections have resulted in a shift in sentencing philosophy that now emphasizes selective incarcerate and sentencing more offenders to the community. Many of these offenders are considered high risk, suffering from serious mental health problems and addictions to drugs and alcohol. Importantly, these high risk offenders are also more likely to be unemployed or holding low paying jobs. ${ }^{7}$ The Great Recession of 2008 has impacted budgetary allocations to local community-based corrections agencies. Many agencies do not have adequate resources to supervise and provide rehabilitation services to meet the needs of higher risk offenders and to keep communities safe. Consequently, it is incumbent upon community corrections agencies to increase the rate at which fees are collected in order to pay for unmet budgetary needs.
Although additional research is needed to ascertain best practices in fee collection, a survey of the literature provides an excellent foundation to build effective fee collection policies and procedures that will increase the rate at which fees are collected. The current literature suggests that fee collection rates can be markedly improved by making fee collection a priority within agencies, setting fees at reasonable levels, having easy-to-understand fee collection policies and following them, regularly sending reminder notices to offenders about when to pay and how much is owed, and allowing agencies direct access to at least some of the revenues collected through fees so that officers and their support staff see the benefits of their efforts. Increasing fee collection rates helps to fund supervision, monitoring and rehabilitation programs. These programs help to change offenders' lives and encourage conformity to the law. By extension, the programs funded through fee collection can help create more peaceful and safe communities.

\section{Acknowledgments}

None.

\section{Ethical consent}

None.

\section{Conflicts of interest}

The author declares there are no conflicts of interest.

\section{References}

1. Kaeble D, Glaze L. Correctional populations in the United States, 2015. US Department of Justice Office, USA. 2016;1-20.

2. Parent D. Recovering correctional costs through offender fees. US Department of Justice, USA. 1990;1-63.

3. Olson DE, Ramker GF. Crime does not pay, but criminals may: factors influencing the imposition and collection of probation fees. The Justice System Journal. 2001;22(1):29-46.

4. De Michele MT. Probation and parole's growing caseloads and workload allocation: strategies for managerial decision making. The American Probation and Parole Association, USA. 2007;1-70.

5. Baird SC, Holien DA, Bakke AJ. Projecting probation fee revenues: a revenue projection model for agencies based on local policies and demographic data. National Council on Crime and Delinquency, USA. $1986 ; 1-27$.

6. Hillsman ST, Mahoney B. Collecting and enforcing criminal fines: a review of court processes, practices, and problems. The Justice System Journal. 1988;13(1):17-36.

7. Moe YU. Jobs programs gets probationers on the right road. Center for Employment Opportunities, USA. 2015. 